\title{
An orderly charge and discharge control method of considering electric vehicle V2G and photovoltaic complementation in residential area
}

\author{
Shaoxing Zhang ${ }^{1 *}$, Haifeng $\mathrm{Su}^{2}$ \\ ${ }^{1}$ Department of Electrical Engineering, North China Electric Power University, Editorial Department, Baoding, Hebei, China \\ ${ }^{2}$ Department of Electrical Engineering, North China Electric Power University, Editorial Department, Baoding, Hebei, China
}

\begin{abstract}
In order to resolve the problems of distribution network overload and increased peak-valley difference caused by large-scale electric vehicles' disordered charging, taking the residential community as the research object, an orderly charging method of electric vehicles (EVs) based on power line carrier communication was proposed, and a model of ordered charge and discharge control and load peak regulation considering the complementary of EVs V2G and photovoltaic (PV) was established. It makes full use of the ability of EVs to cut peaks and valleys and restrain the fluctuation of PV output, alleviates the load pressure of the distribution network and reduces the cost of network transformation, which not only brings great benefits to the owners of EVs and power supply operators, but also promotes the consumption of new energy.
\end{abstract}

\section{Introduction}

With the rapid development of distributed generation technology, a large number of distributed PV power generation has been installed in residential areas. The randomness and intermittency of the injected power bring new challenges to the operation of the distribution network [1]. With the increasing popularity of EVs and the continuous improvement of residential charging facilities, on the one hand, large-scale disorderly charging of EVs will form the phenomenon of load peak on top of load peak of distribution network, which will aggravate the burden of distribution network. On the other hand, it is expected to combine EVs with PV energy through V2G technology to slow down the load fluctuation of the distribution network and promote the penetration and absorption of PV energy.

There have been many related studies on the charging control methods of photovoltaic power generation and EVs access to distribution network. Reference [2] has studied the optimal scheduling methods of EVs PV charging stations with the aim of reducing the power purchase cost and the circulating quantity of battery pack as the optimization goals. Reference [3] has studied the joint scheduling of distribution systems with distributed PV and EV charge and discharge. Reference [4] has proposed a new optimization model of time-of-use electricity price in the case of considering distributed PV power. Reference [5] studied the charging and discharging model of EV in V2G mode. Reference [6] studied the cooperative load control problem of wind power, PV power generation and EV.
According to the charging characteristics of EVs and the characteristics of $\mathrm{PV}$ power generation, taking residential area as the research object and aiming at maximizing power supply benefits, this paper considers the complementary of EVs and PV power generation through V2G technology, has established a model which takes into account the economic interests of both grid operators and EV users, and verifies this through simulation, and its effectiveness is verified by simulation

\section{The models of EVs and PV in residential area}

\subsection{The stay and SOC distribution of private EVs}

According to reference [6], the return time of private EVs approximately satisfies the normal distribution $t \sim \mathrm{N}(17.6,3.4)$, and the daily mileage approximately obeys the log-normal distribution $d \sim \log \mathrm{N}(3.2,0.88)$. According to the driving rules of private EVs, the travel of $400 \mathrm{EVs}$ in the residential community has been simulated. It is assumed that $90 \%$ of the vehicles have travel needs, and the distribution of 24-hour vehicle residence (Figure 1) and the SOC state distribution (Figure 2) in the residential community are obtained. As can be seen from the figure, the number of electric cars staying in the community keeps increasing in the afternoon. After 17:00, there are enough EVs and sufficient discharge power in the community to PV in V2G peak clipping and valley filling. 


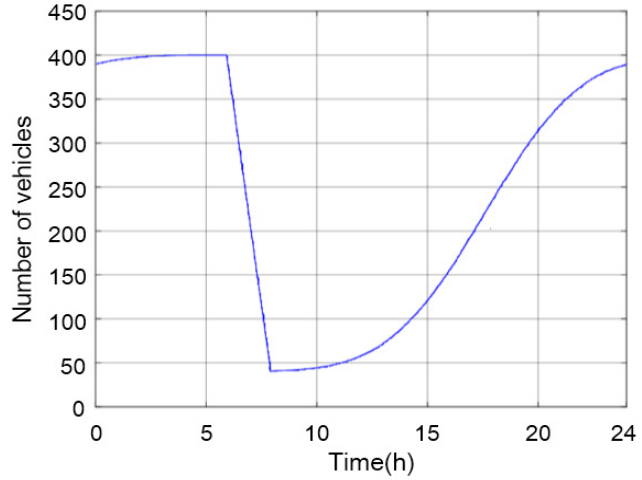

Figure 1. Residence distribution of EV in the community

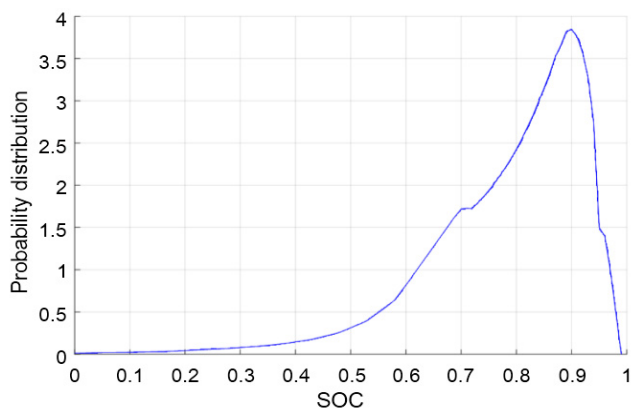

Figure 2. SOC distribution of EV after return

\subsection{The model of EVs responding to V2G participation}

The difference between peak and valley electricity price is used to attract EV users to participate in V2G peakvalley clipping. According to the price elasticity coefficient of power demand side response and the V2G data survey of EV users' participation, the relationship between users' V2G participation and arbitrage returns is shown in equation (1).

$$
\lambda=\left\{\begin{array}{l}
0, \quad \Delta p<0.3 \\
1.0 \times \Delta p-0.1,0.3 \leq \Delta p<0.6 \\
2 \times \Delta p-0.7,0.6 \leq \Delta p<0.8 \\
0.9,0.8 \leq \Delta p
\end{array}\right.
$$

In the above equation, $\lambda$ is the EV users' percent of participation, $\Delta p$ is the net income of EVs for V2G discharge $1 \mathrm{kWh}$ and its unit is yuan $/ \mathrm{kWh}$.

\subsection{The model of PV power generation system}

The sunlight has a strong characteristic of time regularity. Studies have shown that the solar light intensity meets Beta distribution at a certain moment [7].

$$
f(r(t))=\frac{\Gamma(\alpha+\beta)}{\Gamma(\alpha) \Gamma(\beta)}\left(\frac{r(t)}{r_{\max }(t)}\right)^{\alpha-1}\left(1-\frac{r(t)}{r_{\max }(t)}\right)^{\beta-1}
$$

In the above equation, $\Gamma$ is the Gamma function, $r(t)$ is the intensity of sunlight, $\alpha$ and $\beta$ are shape parameters of Beta distribution.

The output function of the PV power generation system is expressed as:

$$
P_{S}(t)=r(t) A \eta\left(1-k_{T} \delta T\right)
$$

In the above equation, $A$ is the total area of the $\mathrm{P}$ power generation array, $\eta$ is the photoelectric conversion efficiency, $k_{T}$ is the temperature coefficient provided during the production of PV cells, $\delta T$ is the prediction error of battery temperature.

\section{The profit model of V2G charging and discharging for EVs}

Grid operators could save distribution network costs through V2G peak shaving and valley filling. EV users could obtain certain economic benefits through the charging and discharging price difference and subsidies from operators. The key is that only the proper user participation could be able to maximize the benefits of grid operators.

\subsection{Orderly charging and discharging profit model of EVs}

A mathematical model was established with the maximization of total revenue of power supply operators as the objective function, and the V2G participation of EVs $(\lambda)$ and the peak load percentage $(\varphi)$ as the optimization variables to establish the objective function of the orderly charge-discharge revenue model of EVs $\mathrm{V} 2 \mathrm{G}$, as shown in equation (4).

$$
C_{\max }=C_{\text {save }}-C_{\text {sup }}
$$

In the above equation, $C_{\text {save }}$ is the reduced capacity expansion cost, operation and maintenance cost and peak regulation income of the distribution network after reducing the peak load; $C_{\max }$ is the subsidy cost paid to $\mathrm{EV}$ users to encourage $\mathrm{EV}$ to participate in $\mathrm{V} 2 \mathrm{G}$ discharge. Among them:

$$
\begin{gathered}
C_{\text {save }}=C_{T}+\Delta P_{I o-T}+0.4 \Delta P_{k-T}+C_{\text {line }}+ \\
\\
\Delta P_{\text {Line }}+C_{M}+C_{s u}
\end{gathered}
$$

In the above equation, $C_{T}$ is the transformer investment and installation cost saved; $\Delta P_{I o-T}$ is the noload loss cost of transformer saved; $\Delta P_{K-T}$ is the transformer load loss cost saved; $C_{\text {Line }}$ is the cost of line investment and installation saved; $\Delta P_{\text {Line }}$ is the line loss cost saved; $C_{M}$ is the annual operating cost of medium and low voltage distribution network; $C_{s u}$ is the cost of peak regulation subsidy.

\subsection{Orderly charging and discharging profit model of EVs taking into account PV consumption}

After the PV power generation system is connected in, the V2G discharge power of EVs can be divided into two parts: one part participates in the form of peak clipping, valley filling and energy storage arbitrage; the other part participates in the form of eliminating PV power output 
fluctuations. Taking the optimal EV V2G participation $(\lambda)$, percentage of peak load $(\varphi)$ and distributed PV installation capacity as the optimization variables, the objective function of the mathematical model of EV orderly charge-discharge earnings considering PV energy consumption and V2G is shown in equation (6).

$$
C_{\text {max }}=C_{\text {save }}+C_{P V-e a r n}-C_{\text {sup }}-C_{P V \text {-sup }}
$$

In the above equation, $C_{P V-e a r n}$ is the annual net income of PV power generation; $C_{P V \text {-sup }}$ is the subsidy cost of EVs participating in the regulation of photovoltaic output fluctuation. Among them:

$$
C_{P V \text {-earn }}=p_{P V} * Q_{P V}-C_{P V}-C_{P V-M}-C_{E V-r e}
$$

In the above equation, $p_{P V}$ is the on-grid price of $\mathrm{PV}$ power; $Q_{P V}$ is the annual PV power generation; $C_{P V}$ is the equivalent annual cost of $\mathrm{PV}$ investment; $C_{P V-M}$ is the annual operation and maintenance cost of $\mathrm{PV}$ equipment; $C_{E V-r e}$ is the cost attached to EVs to suppress fluctuations in PV output.

\section{Sequential charge and discharge control method for EVs in residential quarters}

This article adopts the method of combining peak-valley time-of-use electricity price and power carrier communication to realize the orderly charging and discharging of EVs.

\subsection{Peak and valley time price}

The peak and valley electricity prices are used to guide users to actively change their electricity consumption behaviors, to perform V2G discharge during peak periods and charge during valley periods, so as to achieve the purpose of peak shaving and valley filling. The peak and valley electricity prices of residential areas are shown in Table 1.

Table 1. Electricity price table of residential quarters

\begin{tabular}{|c|c|c|}
\hline Type & Time & Price \\
\hline Peak & $6: 00-22: 00$ & $p_{p}$ \\
\hline Valley & 22:00-6:00 & $p_{v}$ \\
\hline
\end{tabular}

In the Table $1, p_{p}$ is the peak period electricity price, $p_{v}$ is the price of grain time.

\subsection{Orderly charging control method based on power line carrier communication}

The orderly charging scheme of EVs based on power carrier communication is to obtain the total load level of the distribution system in real time by each charging pile through the mode of carrier broadcast communication. According to the total load level of the system, EVs with appropriate conditions are selected for orderly charging in the load valley period. The system is shown in Figure 3.

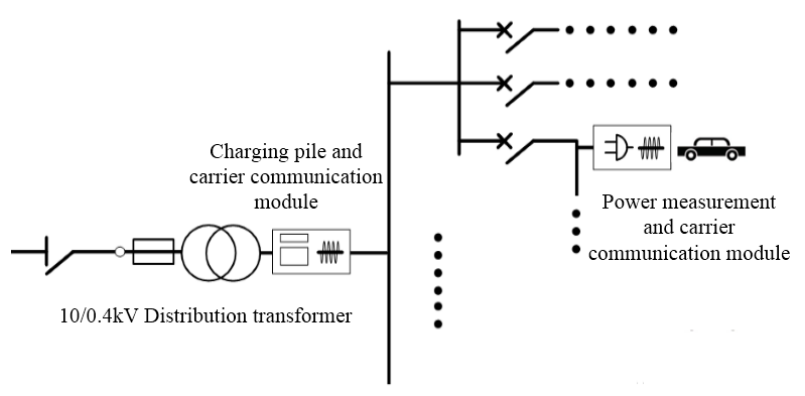

Figure 3. Schematic diagram of power carrier communication

The implementation process of orderly charging and discharging of EVs based on power line carrier communication is as follows:

(1) Install the power measurement and carrier communication transmission module at the main switch of the distribution transformer, and set the power limit threshold.

(2) Install the carrier communication receiving module at each charging pile.

(3) The power measurement module measures the total power of the bus at a certain time interval, and sends the measured value and the maximum power limit threshold through carrier communication.

(4) The carrier receiving module on the charging pile receives the carrier information.

(5) When the EV is connected to the charging pile, the control strategy as shown in Figure 4 is used to control the EV for orderly charging.

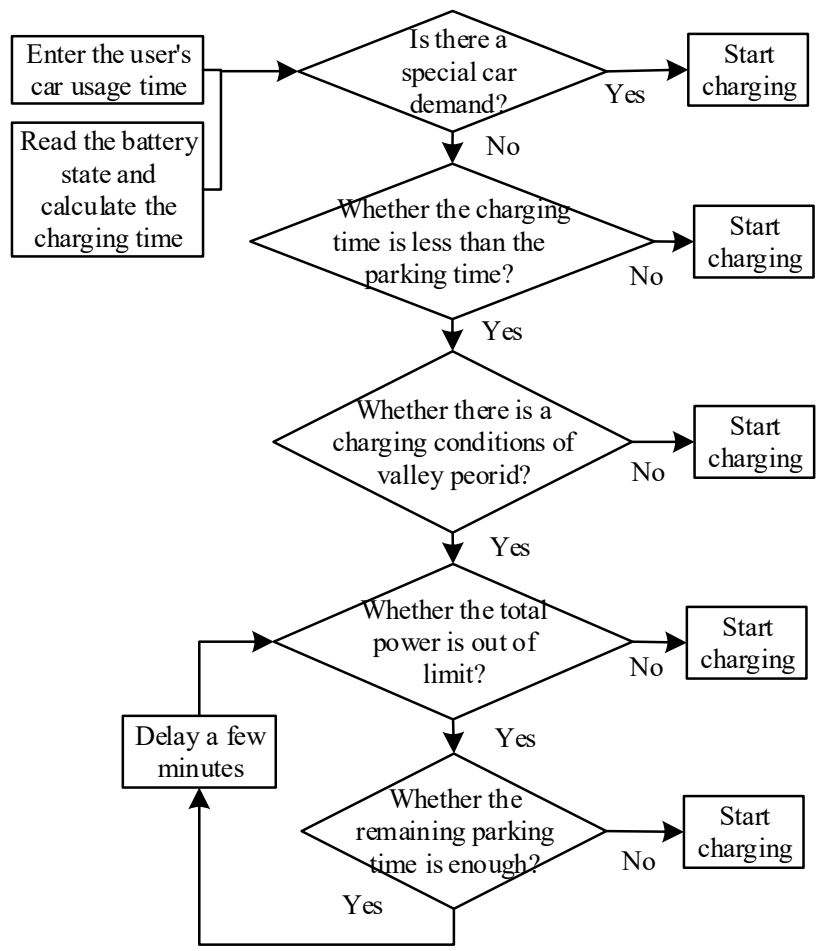

Figure 4. Orderly charging flow chart based on carrier communication

\section{Example analysis}

A residential community with 750 houses is taken as an example with $400 \mathrm{EVs}$ for simulation. The types of EVs and their related parameters are shown in Table 2. The 
average investment of unit distribution capacity is 100 yuan $/ \mathrm{kVA}$. The average load loss is $0.004 \mathrm{~kW} / \mathrm{kVA}$. The unit investment of PV power generation is 4000 yuan $/ \mathrm{kW}$. The on-grid price of PV power is 0.75 yuan $/ \mathrm{kW}$. Charging price during the valley time is 0.3 yuan $/ \mathrm{kWh}$ and the price of discharge during the peak time is 1.3 yuan $/ \mathrm{kWh}$. Peak shaving subsidy for electric vehicles is 0.35 yuan $/ \mathrm{kW}$.

\begin{tabular}{|c|c|c|c|c|}
\hline Type & $\begin{array}{c}\text { Kilometre } \\
\text { power } \\
\text { consumption } \\
\mathrm{kWh} / \mathrm{km} \\
\end{array}$ & $\begin{array}{c}\text { Slow } \\
\text { charging } \\
\text { power/k } \\
\text { W }\end{array}$ & $\begin{array}{c}\text { Quick } \\
\text { charging } \\
\text { power/kW }\end{array}$ & $\begin{array}{c}\text { Propor } \\
\text { tion }\end{array}$ \\
\hline Leaf & 15 & 3 & 48 & $50 \%$ \\
\hline E30 & 18 & 4.8 & 58 & $30 \%$ \\
\hline E6 & 21 & 15 & 120 & $20 \%$ \\
\hline
\end{tabular}

\subsection{Income from orderly charging and discharging of EVs}

The average load rate of transformer is $40 \%$, the saved line investment and loss cost are $70 \%$ and $30 \%$ of the saved transformer investment respectively, and the annual operation cost of distribution network is $15 \%$ of the initial investment. According to the above conditions, the simulation and optimization results obtained are shown in Table 3, Table 4 and Figure 5.

As can be seen from Table 3 , after orderly charging and discharging regulation of EVs in $\mathrm{V} 2 \mathrm{G}$ mode, the original peak load of the community decreases from $3080 \mathrm{~kW}$ to $2955 \mathrm{~kW}$, and the peak load demand is reduced by $125 \mathrm{~kW}$. The daily load change curve of the system is shown in Figure 5. It can be seen that after regulation, the system load is smoother and the peaking valley difference is also significantly reduced.

As can be seen from Table 3 and 4, when the percentage of peak load is set to 0.96 and the V2G participation is 0.3 , after optimizing the orderly charge and discharge control strategy of EVs, the power grid operator can earn 198,445 yuan per year. It includes 9,955 yuan of revenue from slowing down the transformation and expansion of the distribution network, and 188,490 yuan from EV V2G peak cutting and valley filling.

Table 3. Ordered charge and discharge parameter information

\begin{tabular}{|c|c|c|c|c|c|}
\hline $\begin{array}{c}\text { Max } \\
\text { load/k } \\
\mathrm{W}\end{array}$ & $\begin{array}{c}\text { Min } \\
\text { load/k } \\
\mathrm{W}\end{array}$ & $\begin{array}{c}\text { The peak } \\
\text { valley } \\
\text { difference/ } \\
\mathrm{kW}\end{array}$ & $\varphi$ & $\lambda$ & $\begin{array}{c}\text { Average } \\
\text { daily peak } \\
\text { shaving/kW } \\
\mathrm{h}\end{array}$ \\
\hline 2955 & 2017 & 941 & 0.96 & 0.3 & 2065 \\
\hline
\end{tabular}

Table 4. Income information of orderly charge and discharge

\begin{tabular}{|c|c|c|c|}
\hline \multicolumn{2}{|c|}{ Total annual net income/yuan } & \multicolumn{2}{c|}{198445} \\
\hline \multicolumn{3}{|c|}{ Reduce the distribution network expansion cost } \\
\hline $\begin{array}{c}\text { Save the annual } \\
\text { value of } \\
\text { investment/yuan }\end{array}$ & \multicolumn{2}{|c|}{$\begin{array}{c}\text { Saving operation } \\
\text { cost/yuan }\end{array}$} & $\begin{array}{c}\text { Total } \\
\text { revenue/yua } \\
\mathrm{n}\end{array}$ \\
\hline 2085 & \multicolumn{2}{|c|}{7870} & 9955 \\
\hline \multicolumn{3}{|c|}{ Equal annual value of V2G peak shaving revenue } \\
\hline $\begin{array}{c}\text { Peak shaving } \\
\text { profit/yuan }\end{array}$ & $\begin{array}{c}\text { EV } \\
\text { battery } \\
\text { subsidy } \\
\text { costs/yuan }\end{array}$ & $\begin{array}{c}\text { Net } \\
\text { income of } \\
\text { peak } \\
\text { shaving of } \\
\text { EV /yuan }\end{array}$ & $\begin{array}{c}\text { V2G net } \\
\text { income/yua } \\
\mathrm{n}\end{array}$ \\
\hline 1017847 & 527773 & 301584 & 188490 \\
\hline
\end{tabular}

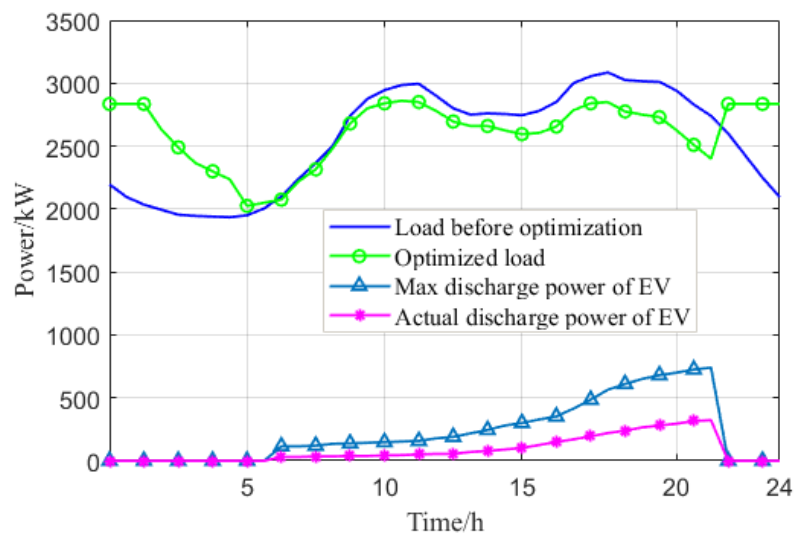

Figure 5. Power and load curves in V2G mode

\subsection{Orderly charging and discharging income of EVs taking into PV}

Assume that the annual operation and maintenance cost of PV equipment is 60 yuan $/ \mathrm{kW}$, and $20 \%$ of the gross revenue of PV power generation is taken as the subsidy for EVs to suppress the fluctuation of PV power output. The simulation and optimization results obtained are shown in Table 5, Table 6 and Figure 6.

As can be seen from Table 5, when the orderly charge-discharge strategy of EVs combining PV energy is adopted, the peak load decreases from $2955 \mathrm{~kW}$ to $2869 \mathrm{~kW}$, and the peak load demand decreases by $86 \mathrm{~kW}$, compared with the V2G mode only. The daily load change curve of the system is shown in Figure 6. It can be seen that the system load curve is smoother, and the peak load and peaking-valley difference are significantly reduced.

According to Tables 5 and 6, when PV installation capacity is $190 \mathrm{~kW}, \mathrm{EV} \mathrm{V} 2 \mathrm{G}$ participation is 0.24 , and load threshold is set to 0.93 , grid operators can earn an annual income of 313,967 yuan after the orderly charging and discharging strategy of EV combined with $\mathrm{PV}$ is adopted.It includes annual income of 17,574 yuan from slowing down the transformation and expansion of distribution network, annual income of 178,490 yuan from EV V2G peak shaving and valley filling, and annual net income of 117,903 yuan from PV power generation system. 
Table 5. The V2G charge-discharge parameters of PV mode

\begin{tabular}{|c|c|c|c|}
\hline $\begin{array}{c}\text { Maximum } \\
\text { load/kW }\end{array}$ & $\begin{array}{c}\text { The peak valley } \\
\text { difference/kW }\end{array}$ & $\begin{array}{c}\text { PV average } \\
\text { daily } \\
\text { output } / \mathrm{kWh}\end{array}$ & $\varphi$ \\
\hline 2869 & 859 & 843 & 0.93 \\
\hline $\begin{array}{c}\text { Minimum } \\
\text { load } / \mathrm{kW}\end{array}$ & $\begin{array}{c}\text { Average daily } \\
\text { peak } \\
\text { shaving } / \mathrm{kWh}\end{array}$ & $\begin{array}{c}\mathrm{PV} \\
\text { capacity } / \mathrm{kW}\end{array}$ & $\lambda$ \\
\hline 2010 & 1666 & $190 / \mathrm{kW}$ & 0.24 \\
\hline
\end{tabular}

Table 6. Various costs and benefits of PV and V2G mode

\begin{tabular}{|c|c|c|c|}
\hline \multicolumn{2}{|c|}{ Annual net income/yuan } & \multicolumn{2}{|c|}{313967} \\
\hline \multicolumn{4}{|c|}{ Reduce the cost of distribution network expansion } \\
\hline $\begin{array}{l}\text { Save the annual } \\
\text { value of } \\
\text { investment/yuan }\end{array}$ & \multicolumn{2}{|c|}{ Saving operation cost/yuan } & $\begin{array}{c}\text { Total } \\
\text { revenue } \\
\text { /yuan }\end{array}$ \\
\hline 3680 & \multicolumn{2}{|c|}{13894} & 17574 \\
\hline \multicolumn{4}{|c|}{ Equal annual value of $\mathrm{V} 2 \mathrm{G}$ peak shaving revenue } \\
\hline $\begin{array}{l}\text { Peak shaving } \\
\text { profit/yuan }\end{array}$ & $\begin{array}{l}\text { EV battery } \\
\text { subsidy } \\
\text { costs/yuan }\end{array}$ & $\begin{array}{l}\text { Net income } \\
\text { of peak } \\
\text { shaving of } \\
\text { EV }\end{array}$ & $\begin{array}{c}\text { V2G net } \\
\text { income/ } \\
\text { yuan }\end{array}$ \\
\hline 807800 & 423574 & 205736 & 178490 \\
\hline \multicolumn{4}{|c|}{ Annual net income from PV power generation } \\
\hline $\begin{array}{l}\text { Annual value of } \\
\text { investment, } \\
\text { operation and } \\
\text { maintenance/yua } \\
\text { n }\end{array}$ & $\begin{array}{l}\text { Annual } \\
\text { gross } \\
\text { revenue } \\
\text { from PV } \\
\text { /yuan }\end{array}$ & $\begin{array}{l}\text { PV } \\
\text { fluctuations } \\
\text { suppress } \\
\text { costs/yuan }\end{array}$ & $\begin{array}{l}\text { Net } \\
\text { revenue } \\
\text { from } \\
\text { PV } \\
\text { /yuan }\end{array}$ \\
\hline 88806 & 258387 & 51677 & 117903 \\
\hline
\end{tabular}

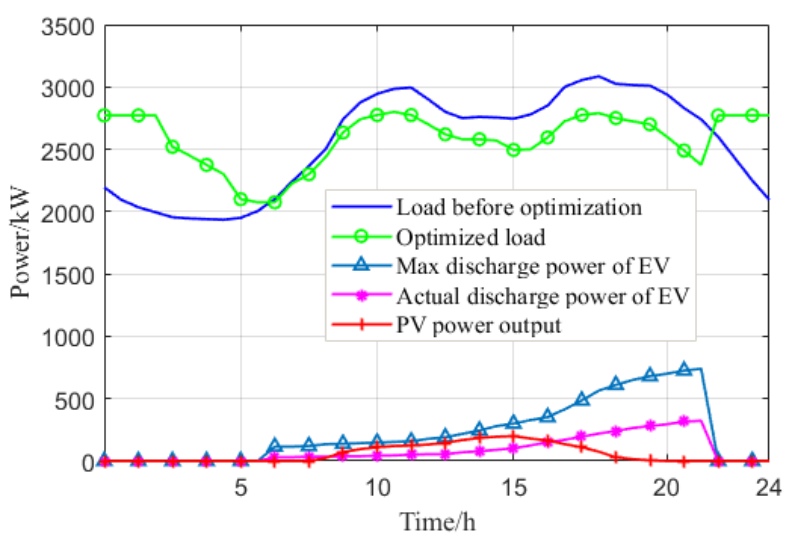

Figure 6. Power and load curves of V2G mode and PV

\section{Conclusion}

From the perspective of grid operators, this article also takes into account the interests of EV users, has established an orderly charging and discharging control and load peak shaving model for EVs in residential areas that take into account V2G EVs and PV complements, and has conducted the simulations. The conclusions are as follows: (1) EVs reasonably participate in V2G discharging and conduct scientific and orderly charging, which brings relatively substantial benefits to grid operators and EV owners; (2) The orderly charging and discharging model of EVs that takes into account PV and V2G can more effectively reduce load peaks and reduce peak-to-valley differences, and the total system revenue is also higher, while also effectively promoting the consumption of clean energy power generation.

\section{Acknowledgments}

This paper was supported by the National Key R \& D Program of China(2017BJ0080).

\section{References}

1.Z. Wang. Influence of distributed photovoltaic on distribution network and countermeasures. J. Communication power supply technology, 36(12):246-247(2019)

2.X.Y. Lu, N. Liu, Z. Chen, et al. Multi-objective optimization scheduling method for photovoltaic charging station of electric vehicles. J. Journal of electrotechnics, 29(08):46-56(2014)

3.X.T. Xu, Y.F. Zhang, G.G. Chen, et al. Research on charging optimization scheduling of electric vehicles including photovoltaic power generation. J. Intelligent power, 47(10):44-50(2019)

4.M.K. Li, Y.S. Zhang. Research on time-of-use price Model for Distributed Photovoltaic power generation. J. Power Grid and Clean Energy, 34(04):74-78(2012)

5.Z.H. Chen, C.Q. Wang, J.M. Chen, et al. Study on orderly charge and discharge control model of electric vehicles in $\mathrm{V} 2 \mathrm{G}$ mode. J. Zhejiang electric power, 38(08):37-42(2019)

6.H.J. Liu. A Model and Method for Collaborative Load Control of Wind Power, Photovoltaic Power Generation and Electric Vehicle. J. Journal of Electromechanical Systems and Its Automatic Chemistry, 27(S1):12-17(2015)

7.T. Zhang, D.F. Zhang, L.Y. Wang, et al. Multiobjective Optimization and Reconstruction of Active Distribution Network Considering Electric Vehicle Charging Mode. J. Power System Protection and Control, 46(08):1-9(2018)

8.W.Z. Guo, G.L. Chen, Z. Chen. A review of discrete particle swarm optimization algorithms. J. Journal of Fuzhou university (natural science edition), 39(05):631-638(2011) 